\title{
DISASTER-RELATED PHYSICAL AND MENTAL HEALTH: A ROLE FOR THE PHYSICIAN
}

The American Red Cross defines a disaster as involving 100 or more persons, 10 or more deaths, or an appeal for assistance. ${ }^{1}$ Qualifying events include natural disasters (e.g., hurricanes, earthquakes, floods, tornadoes), technologic disasters (e.g., nuclear or industrial accidents), and mass violence (e.g., terrorist attacks, shooting sprees). Disasters always have been a part of life, whether caused by unavoidable natural events or by avoidable, man-made events. Being rendered helpless by such events has caused fear and concern in all periods of history. To some extent, a disaster is expected, but there are varying degrees of uncertainty as to how and when it will occur. The occurrence of a disaster creates varying degrees of chaos combined with a mismatch between resources and needs. Therefore, in order to restore an affected society back to its pre-event status requires extraordinary efforts.

Disasters continue to increase in frequency and severity worldwide. The costs associated with these catastrophes continue to skyrocket in an unanticipated manner. These costs can be quantified in human, economic, and intangible terms. Human costs generally are computed on the basis of numbers of persons killed. Each disaster and its context are different, yet many share similar health sector vulnerabilities and thus common disaster management practices and policies can be built in to the health system to create resilience the 'all-hazards' approach.

Five recent major disasters exemplify the need for strengthened health systems. The earthquake in Haiti, $12^{\text {th }}$ Jan 2010, left 1.5 million homeless and killed 149,095 people of which 6300 died in a potentially preventable cholera outbreak which infected a further 450,000 residents. ${ }^{2}$ Haiti lacked an effective health system prior to the earthquake and national authorities were not equipped to manage relief or recovery priorities when the disaster occurred. ${ }^{3}$ Governance structures were destroyed and the required services, health workers, surveillance, resources, funding and (attempts at) coordination were provided almost completely by international organizations, creating its own set of complications and delaying investments into the health system. ${ }^{4}$ Floods in Pakistan, July to August 2010, affected 20 million people and destroyed health facilities. In spite of the public health challenges, previous disaster management investment in southern Punjab region allowed for effective evacuations and saved lives. ${ }^{5}$ The famine in the Horn of Africa in 2011 affected 10 million people across several countries. Large population displacement created additional public health challenges to areas that have poorly developed health systems and lack disaster preparedness. Immediate priorities included - provision of water, sanitation, and shelter; trained staff to address widespread acute malnutrition; surveillance for outbreaks; vaccine programmes for preventable diseases; funding; and inter-agency coordination. ${ }^{6}$ These reflect the different components of a health system. The earthquake and tsunami in Japan, $11^{\text {th }}$ March 2011, caused destruction of healthcare facilities; initial shortages of food, water, fuel, aid materials and rescue teams to the affected rural population; 400,000 people were evacuated to shelters with no heating in freezing temperatures. However, Japan had invested in disaster management and had created a more resilient health system which continued to function in spite of the challenges. ${ }^{7}$ It was on the $24^{\text {th }}$ April 2013 that a building named "Rana Plaza" at Savar in Dhaka, Bangladesh collapsed killing over thousand people and injuring another 2438. 
The 9-storied building housed shopping centre, bank, garment factories and other commercial offices. It is estimated that on an average day near about four thousand people used to work in the building. The latest available information at the time of writing this article on $12^{\text {th }}$ May evening is that 1117 dead bodies have been recovered and 2438 have been rescued alive. ${ }^{8}$ Quite a few are still not accounted for. Amongst the rescued perhaps a few more may have succumbed to their injuries and over hundred have become permanently disabled. This makes the incident worst industrial tragedy only second to the Union Carbide disaster in Bhupal, India.

A person's response to a disaster is determined by demographic and socioeconomic factors, as well as the person's pre-disaster mental health and the extent of his or her social support before, during, and after the event. Regarding demographic factors, children typically display emotional distress when family conflict occurs; middle-age adults experience psychological and physical problems when a disaster makes it impossible to meet responsibilities and older adults most often display post-disaster physical and mental health problems when limits on income, health, or social support before the disaster result in an inability to cope effectively after the disaster. $9,10,11,12$

In general, ethnic minority status and lower income have been associated with poorer postdisaster physical and mental wellbeing. Although being married appears to help men, a married woman may experience poorer post-disaster adjustment if her marital status results in her giving out more social support than she receives.

Pre-disaster life events also may have an impact on post-disaster physical and mental health. Exposure to traumatic events has been associated with a range of mental health problems (e.g., post-traumatic stress disorder [PTSD]) that can impact post-disaster response. Less intensely stressful life events (e.g., financial or marital problems) existing one year before disaster exposure have been associated with increased physical and psychological symptom reports.
In terms of mental health, a history of predisaster symptoms can predict the presence of post-disaster symptoms. Also, persons with predisaster mental health histories are more likely to display post-disaster mental health problems including PTSD. ${ }^{12}$

Predictors of effective coping can help triage less-needy patients. Coping refers to cognitive and behavioral abilities to solve problems, manage emotions, or disengage from difficult problems or emotions. ${ }^{11}$ In general, successful coping is characterized by flexibility, creative thinking, willingness to try new things, action orientation, working cooperatively with others, and the ability to tolerate frustration or other strong emotions.

The impact of pre-disaster social support on post-disaster well-being is complex. Generally, victims' post-disaster adjustment can be improved if they perceive that they are supported, if they receive more support than they give, or if they are embedded in a healthy social network

Within a disaster, exposure has objective (e.g., serious injury, death) and perceived (e.g., sensing threat to life) elements. High levels of disaster exposure increase the risk of developing PTSD or other severe mental health problems following the disaster. 4 Family physicians must be comfortable in tactfully, directly, and privately asking patients about exposure to within-disaster mental health risk factors.

Physicians are well suited to address the physical and mental health needs of disaster victims. Disaster exposure increases primary health care use for 12 months or more after the event. More importantly, the acute and chronic physical and mental health issues that most commonly occur after a disaster are within the scope of practice for family physicians and other board-certified primary care physicians.

\section{Common Post-Disaster Health Outcomes}

The probability of a particular post-disaster physical or mental health condition varies according to the time since the disaster onset. It is helpful to divide the post-disaster time 
frame into acute (less than one month), intermediate (one to 12 months), or long-term (i.e., chronic; longer than 12 months) phases. Physical problems fall into four categories: (1) acute injuries; (2) acute problems; (3) chronic problems; and (4) medically unexplained physical symptoms.

\section{Physical health}

- Acute injuries- Examples: Gastroenteritis or dehydration; head lice; pulmonary problems; rashes; rodent-borne illness; selflimited viral syndrome; toxic exposures; vector-borne illness.

- Acute problems-Examples: Gastroenteritis or dehydration; head lice; pulmonary problems; rashes; rodent-borne illness; selflimited viral syndrome; toxic exposures; vector-borne illness.

- Chronic problems- Examples: Congestive heart failure; diabetes; hypertension; pulmonary problems (e.g., chronic obstructive pulmonary disease, acute bronchitis, asthma)

- Medically unexplained physical symptoms- Examples: Fatigue; gastrointestinal complaints; headaches; other generally vague somatic complaints without clear organic etiology

\section{Mental health}

- Acute responses- Examples: Cognitive dysfunction or distortion; dysfunctional interpersonal behaviors; emotional lability; nonorganic physical symptoms

- Chronic problems-Examples: Alcohol abuse or dependence; depression; interpersonal violence; PTSD or other anxiety disorders; schizophrenia or other severe chronic disorders

- New-onset mental health problemsExamples: Acute stress disorder possibly evolving to post-traumatic stress disorder (PTSD); alcohol abuse or dependence; depression; interpersonal violence.

More than one half of acute post-disaster health issues are illnesses (e.g., self-limited viral syndromes, gastroenteritis) .Approximately one fourth of acute post-disaster health complaints are injuries (e.g., cuts, abrasions, sprains, fractures). Other acute post-disaster health issues include routine items such as medication refills, wound checks, and splinting. 13

It is common for disaster victims to require assistance in the management of chronic health problems (e.g., diabetes, hypertension, $\mathrm{CHF}$ ). Simple provision of medication and medical supplies may be sufficient. Depending on the degree to which the disaster has impacted community infrastructure, such assistance may be required as part of the intermediate or even long-term phase of postdisaster adjustment.

Somatic complaints without organic cause, sometimes described as medically unexplained physical symptoms, are common following a disaster. These unexplained symptoms also are associated with mental health problems such as depression, PTSD, and other anxiety disorders. Physicians should increasingly consider a mental health explanation for vague, unexplained physical symptoms as time since the disaster increases.

Mental health outcomes

Most patients with post-disaster mental health problems had similar problems before the disaster occurred. In such cases, the role of the family physician includes the provision of medication refills, supportive counseling, and appropriate referrals when indicated and feasible.

Acute post-disaster psychological distress includes emotional lability; negative emotions; cognitive dysfunction and distortions (e.g., reduced concentration, confusion, unwanted thoughts or memories); physical symptoms (e.g., headaches, tension, fatigue, gastrointestinal upset, appetite changes); and behaviors that negatively affect interpersonal relationships (e.g., irritability, distrust, withdrawal, being overly controlling). For most persons, acute psychological distress will resolve within weeks to several months, but it can persist for up to one year. Distress tends to resolve as victims are able to reliably meet their basic needs. ${ }^{14}$

More severe new-onset mental health problems can occur, with the presentation ranging from 
obvious to subtle. The most common postdisaster mental health problems appear to be depression, PTSD, and other anxiety disorders. $\frac{8}{}$ Increases in alcohol or drug abuse and domestic or interpersonal violence also have been noted. Physicians should consider screening for common mental health problems among vulnerable populations, such as persons with a history of mental health issues, perceived life threat, serious injury, or exposure to death.

A two-stage mental health screening process is recommended. If a disaster victim is thought to be at high risk because of mental health history or within-disaster experiences, that person should be asked directly about exposure to toxic stressors .If initial screening suggests heightened mental health risk, the person should be asked further symptom-based screening questions.

Another way to view the post-disaster time frame is in terms of the potential to experience a series of chronic low-level stresses that may overwhelm coping resources. Physician can be key agents in lessening post-disaster physical and mental health reactions. Key points include providing information, remaining empathic, encouraging victims to seek and accept assistance, advocating selfdetermination to the extent feasible, reminding persons of how they may have successfully coped with previous troubles, and repeatedly checking on disaster victims for up to 12 months (or longer for more severely devastating events).

Physical and mental health effects of disasters often coexist. In some instances, physical problems may increase the probability of mental health problems. For example, a disaster may exacerbate a chronic health condition such as diabetes or congestive heart failure $(\mathrm{CHF})$, with worsening physical health contributing to the development or exacerbation of depression. The reverse direction of causality is possible, with mental health problems resulting in poorer health maintenance efforts and deterioration in chronic health problems.

\section{Disaster Preparation}

Unfortunately disaster management has tended to emphasize the immediate response needs and has neglected the pre-event mitigation and post-event recovery needs of communities. A four-step disaster preparation plan is suggested so that when disasters happen, physicians are able to turn their collective knowledge and skills into compassionate and competent action. This plan includes education, linking up with other organizations, logistical preparation, and personal preparation.

\section{Education:}

All physicians should educate themselves thoroughly about disaster-related physical and mental health threats and also know about threats that may impact a community, including bioterrorism, terrorism, and mass casualty events. Physicians within certain geographic regions also should educate themselves regarding natural disaster events particular to their area.

\section{Linking:}

Many opportunities exist to proactively apply professional knowledge and skills by becoming involved in existing disaster preparedness efforts. Because the scope of many disasters exceeds local health care capacity, it is important for physicians to become embedded in organizations that are most likely to be called on to meet post-disaster community health needs. Opportunities at a local or state level include disaster response teams or planning committees at local hospitals, country and state medical societies, and local and state health departments. To find opportunities at a national level, contact the medical organization of the affected states or other national-level organizations.

\section{Logistical preparation:}

Within each organizational response unit (e.g., clinic, hospital, community health center), a several-week supply of frequently needed items should be available (e.g., medications for common medical and psychiatric problems; suture, splint, and casting materials; educational materials). Outside sources of help are typically unavailable or unreliable for several weeks to one month after a disaster, so the availability of local health care resources is crucial to community well-being. 


\section{Personal preparation:}

Physicians who practice within disasterstricken communities have a dual role. As disaster victims, physicians and their families will be vulnerable to the same physical and mental health outcomes faced by other victims. On the other hand, physicians will want to continue their medical practice for practical and altruistic reasons. It is important to seek a balance between taking care of oneself and one's family versus taking care of patients. Physicians should be prepared to work with other health care professionals in the community to share the collective load in meeting post-disaster health needs; such partnerships should be established well in advance of a disaster. The physicians in a community should be prepared to reach out to and accept assistance from health care professionals outside of the community as well.

\section{Conclusion:}

Generally, disasters have been considered as punishment. However, the mental approach to disasters seemingly is changing as are capabilities to mitigate the impact of the events responsible for them. However, the potential to influence the negative outcomes of such events has not been recognized in an institutional fashion. Also, much of the aid provided was based on intuition and anticipation, not necessarily rooted in understanding and knowledge. Historically, different aspects of disaster management have been considered and discussed in isolation. However, the 'multi-disciplinary health systems' approach to disaster management suggests that each component of a health system needs resilience to threats built in to its structure. In this way, the whole health system can be strengthened to meet the demands of any type of disaster, enabling a coordinated, rapid and effective response and recovery.

Prof. Md. Azizul Kahhar

Professor of Medicine

Dhaka Medical College, Dhaka

\section{References:}

1. International Federation of Red Cross and Red Crescent Societies and the Centre for Research on the Epidemiology of Disasters. World Disasters Report. Norwell: Kluwer Academic Publishers; 1993.

2. WHO. PAHO's Interactive Report of Cholera Outbreak. 2011.

3. PAHO. Health response to the earthquake in Haiti 2010; Lessons to be learned for the next massive sudden-onset disaster. 2011.

4. Responding in a Crisis: The Role of National and International Health Workers - Lessons from Haiti: Merlin; 2010.

5. Oxfam International. Pakistan floods progress report: a report on Oxfam's response to the floods in Pakistan between July 2010 and July 2011. Published in July 2011.

6. WHO. Public health risk assessment and interventions - The Horn of Africa: Drought and famine crisis. Published in July 2011.

7. Matsumoto M, Inoue K. Earthquake, tsunami, radiation leak, and crisis in rural health in Japan. [Editorial]. Rural and Remote Health 2011; 11: 1759.

8. www.The Daily Star.net/13 ${ }^{\text {th }}$ May, 2013.

9. Freedy JR, Resnick HS, Kilpatrick DG. Conceptual framework for evaluating disaster impact: implication for clinical intervention. In: Austin LS. Responding to Disaster: A Guide for Mental Health Professionals. 1st ed. Washington, D.C.: American Psychiatric Press; 1992: 3-23.

10. Norris FH, Friedman MJ, Watson PJ, Byrne CM, Diaz E, Kaniasty K. 60,000 disaster victims speak: part I. An empirical review of the empirical literature, 1981-2001. Psychiatry 2002; 65: 207-39.

11. Norris FH, Friedman MJ, Watson PJ. 60,000 disaster victims speak: part II. Summary and implications of the disaster mental health research. Psychiatry 2002; 65: 240-60.

12. Norris FH, for the Dartmouth Medical School and National Center for PTSD. Range, magnitude, and duration of the effects of disasters on mental health: review update 2005. at:http:// www.redmh.org/research/general/effects.html. [Accessed on December 12, 2012].

13. Centers for Disease Control and Prevention. Surveillance for illness and injury after hurricane Katrina-New Orleans, Louisiana, September 825, 2005. Morb Mortal Wkly Rep 2005; 54: 101821.

14. Young BH, Ford JD, Watson PJ. Survivors of national disasters and mass violence. A National Center for PTSD fact sheet. U.S. Department of Veterans Affairs. at:http://www.ncptsd.va.gov/ ncmain/ncdocs/fact_shts/fs_survivors disaster.html [Accessed on February 20, 2013]. 